\title{
Presse als Medium des gelehrten Gedankenaustausches in der Frühaufklärung
}

\author{
Die Zeitschriftenprojekte des Georg Peter Schultz in Thorn
}

\begin{abstract}
Zusammenfassung: Während für das Königliche Preußen von einem etablierten Pressemarkt erst in den 1760er Jahren die Rede sein kann, entwickelte sich die Presse in Thorn bereits in der ersten Hälfte des 18. Jahrhunderts. Die ersten gelehrten Zeitschriften Thorns waren das Lebenswerk von Georg Peter Schultz (1680 -1748), dem Konrektor des dortigen Akademischen Gymnasiums. Schultz war ein Anhänger von Kopernikus, Pufendorf, Cocceji, Thomasius und Wolff sowie von aktiven Schulreformern. Er legte Nachdruck auf moderne Fremdsprachen, preußische Rechtsgeschichte und Medizin. Seine Zeitschriften, die zwischen 1722 und 1734 herauskamen, waren zunächst vor allem Chroniken der Gelehrtenrepublik. Sie entwickelten sich aber bald zu Periodika, die nicht nur über neue Bücher, akademische Debatten sowie über Vorgänge an der Universität Königsberg und den höheren Schulen des Königlichen Preußen berichteten, sondern auch politische Nachrichten, Dichtung und offizielle Bekanntmachungen druckten. Indem sie nicht auf Latein, sondern auf Deutsch erschienen, konnten Sie auch eine Leserschaft erreichen, die zwar ausgebildet, aber des Lateinischen nicht mächtig genug war. Die Zensur des Stadtrates und der lutherischen Geistlichkeit brachte Schultz schließlich um seine Stelle am Thorner Gymnasium, beendete seine Publikationstätigkeit und zwang ihn zur Auswanderung.
\end{abstract}

Schlagwörter: Thorn; Königliches Preußen; Herzogtum Preußen; Gelehrtenrepublik; Zensur; gelehrte Zeitschriften

\begin{abstract}
While the development of press in Thorn in Royal Prussia reached its first peak in the first half of the eighteenth century, it was not until 1760s that a fully articulated press grew significantly in the region. The establishment of scholarly journals in Thorn was the life's work of Georg Peter Schultz $(1680-1748)$, the deputy headmaster of the post-secondary school in the town. Schultz was an advocate of the works of Copernicus, Pufendorf, Cocceji, Thomasius and Wolff. He tried to reform the school by introducing a curriculum of modern languages, medical science, and through lessons on the legal system of Prussia. His journals, published between 1722 and 1734, developed as chronicles of the scholarly world (Gelehrtenrepublik). Here they contained descriptions of new books and published academic debates as well as news of proceedings at the university of Königsberg and the postsecondary schools of Royal Prussia, going on to accommodate political news, poetry and public announcements. Favouring German over Latin discourse, they became more widely accessible and enabled anyone who was not a Latin-speaker, but was sufficiently educated, to have access to scholarly and political news. The journals were, however, short-lived because of the censorship of town officials and the Lutheran clergy in Thorn.
\end{abstract}

Keywords: Toruń; Royal Prussia; Duchy of Prussia; Gelehrtenrepublik; censorship; scholarly journals

Anna Mikołajewska, Dr., Uniwersytet Mikołaja Kopernika w Toruniu, Katedra Literatury, Kultury i Komparatystyki Niemieckiego Obszaru Językowego, ul. W. Bojarskiego 1, 87-100 Toruń, Polen, nanett@umk.pl 


\section{Einleitung}

Die gelehrte Kommunikation, die sich zwischen dem institutionell organisierten Rahmen von Schulen, Universitäten und Konsistorien sowie der Freiheits- und Gleichheitsforderung der Gelehrten vollzog, fand vor allem in der zweiten Hälfte des 17. und im 18. Jahrhundert in dem sich rasch entwickelnden Medium von Journalen, Zeitungen, Monats- und Wochenschriften statt. Diese publizistischen Formate verhalfen der europäischen Aufklärung zu ihrer großen Breitenwirkung und bildeten einen Stimulus, der den wissenschaftlichen Diskurs wesentlich anregte, intensivierte und diversifizierte. ${ }^{1}$ Zugleich konnte die Kluft zwischen dem Anspruch auf freie Entfaltung einerseits und einem Organisations- und Formzwang andererseits, welche die Respublica litteraria immer schon aufwies, ${ }^{2}$ mit den Periodika nicht überbrückt werden. Als die Presse zum Sprachrohr konkreter politischer Interessen wurde, kam es vielmehr zu neuen Formen obrigkeitlicher Kontrolle.

Eine solche Entwicklung lässt sich am Beispiel von Thorner Presseerzeugnissen des 18. Jahrhunderts aufzeigen, die aufklärerisches Wissen vermittelten und dabei im Einklang mit oder auch in Opposition zu obrigkeitlichen Vorgaben Erinnerungsorte lokaler Geschichte mitbegründeten und -gestalteten. Im Folgenden wird die publizistische Tätigkeit des Thorner Konrektors Georg Peter Schultz in den Blick genommen, der am Akademischen Gymnasium der Weichselstadt als Schulreformer und Begründer ihrer ersten Zeitschriften nach neuen Ausdrucksmöglichkeiten für die aufklärerische Selbstverständigung suchte. Im regen Kontakt mit anderen preußischen Zeitschriftenmachern seiner Zeit arbeitete er daran, seinen mehr oder weniger gebildeten Lesern Orientierungs- und Entscheidungshilfen in der damaligen Situation der Gelehrtenrepublik und des Staates zu liefern. Dabei stieß er sowohl auf ein sinkendes Wohlwollen seitens der lutherischen Obrigkeiten in Reaktion auf seine Erneuerungsversuche als auch auf die zensorische Aufsicht des Stadtrates, der nach dem Thorner Tumult im Jahr 1724 darauf bedacht war, bei den kronpolnischen Behörden keinen Unmut zu erregen.

1 Vgl. Holger Böning: Welteroberung durch ein neues Medium. Die deutsche Presse und der Weg zur Aufklärung. Hamburg und Altona als Beispiel. Bremen 2002, S. 277-283; ders.: Zeitung und Aufklärung. In: Martin Welke, Jürgen Wilke (Hg.): 400 Jahre Zeitung. Die Entwicklung der Tagespresse im internationalen Kontext. Bremen 2008, S. 287-310; Andreas Würgler: Medien in der frühen Neuzeit. München 2009, S. 43-56.

2 Vgl. Sebastian Neumeister, Conrad Wiedemann (Hg.): Res Publica Litteraria. Die Institutionen der Gelehrsamkeit in der frühen Neuzeit. Teil I. Wiesbaden 1987, S. IX. 


\section{Grundlagen des gelehrten Lebens in Thorn}

Im Vergleich zu anderen Provinzen des polnisch-litauischen Staatswesens bot die königlich-preußische Stadt Thorn (Toruń) immer schon einen besonders fruchtbaren Nährboden für die Entwicklung des Zeitschriftenwesens. Während im stark durch Adel und Landwirtschaft geprägten Polen-Litauen lange Zeit kontinuierlich, aber nur in unregelmäßigen Abschnitten erscheinende Serienzeitungen, auf Aktualität abzielende Flugschriften und handgeschriebene Zeitungen das Gesamtbild der Presselandschaft bestimmten, ${ }^{3}$ entwickelte sich in Preußen Königlichen Anteils in Anlehnung an sein deutschsprachiges Patriziat ein Zeitschriftenwesen, das sich an westeuropäischen Vorbildern orientierte. ${ }^{4}$ Nicht ohne Belang war dabei die Tatsache, dass es in Thorn seit 1568 ein Gymnasium gab, welches ein Zentrum des gelehrten Diskurses war. Dieses wurde 1594 in ein elfklassiges Akademisches Gymnasium umgewandelt, wobei die letzte Ausbildungsstufe, die suprema curia, ein zweijähriges Studium mit einem universitätsähnlichen Charakter ermöglichte. ${ }^{5}$ Im Zusammenhang mit dieser Schulreform, die vom Thorner Bürgermeister Heinrich Stroband eingeleitet und entscheidend geprägt wurde, ${ }^{6}$ erschienen in der Weichselstadt drei Bände der Institutio literata, die in der Forschung als pädagogische Zeitschrift bzw. Enzyklopädie bezeichnet und als Auftakt zur Geschichte der Thorner Presse gesehen werden. ${ }^{7}$ Hier erschienen

3 Zum polnischen Pressewesen Mitte des 18. Jahrhunderts vgl. auch den Beitrag von Katarzyna Chlewicka in dieser Themenausgabe. Zur Entwicklung vgl. Konrad Zawadzki: Gazety ulotne polskie i Polski dotyczące XVI-XVIII wieku. Bibliografia [Polnische Flugschriften sowie Flugschriften über Polen aus dem 16.-18. Jh. Bibliographie]. Bd. III. Wrocław 1990; ders.: Początki prasy polskiej. Gazety ulotne i seryjne XVI-XVIII wieku [Anfangsjahre der polnischen Presse. Flugschriften und Serienzeitungen des 16.-18. Jh.]. Warszawa 2002.

4 Komprimiert zu wichtigsten Entwicklungen des 17. und 18. Jhs. auf dem Pressemarkt Polen-Litauens vgl. Henryk Rietz: Entstehung und die Entfaltung der Presse in Polen im 17. und 18. Jahrhundert. In: Welke/Wilke (Hg.), 400 Jahre Zeitung. (wie Anm. 1), S. 231-254.

5 Dies wurde offiziell verkündet in: Orationes $\mathrm{X}$, quarum aliae in actu examinis anniversarii, aliae in inauguratione Novae Curiae, eiusdemque Operarum incohatione, habitae in Gymnasio Thorunensi. Thorn 1595. Vgl. Stanisław Salmonowicz: Kultura umysłowa Torunia w dobie renesansu, reformacji i wczesnego baroku [Geistige Kultur Thorns zur Zeit der Renaissance, der Reformation und des Frühbarocks]. In: Marian Biskup (Hg.): Historia Torunia [Geschichte Thorns]. Bd. II/2. Toruń 1994, S. $169-256$, hier S. 194.

6 Vgl. Henryk Rietz: Henryk Stroband (1548-1609), burmistrz i promotor Gimnazjum Akademickiego w Toruniu [Heinrich Stroband (1548-1609), Bürgermeister und Förderer des Akademischen Gymnasiums in Thorn]. In: Marian Biskup (Hg.): Wybitni ludzie dawnego Torunia [Herausragende Persönlichkeiten des alten Thorn]. Warszawa 1982, S. 37-45.

7 Vgl. Lech Mokrzecki: Studium z dziejów nauczania historii: rozwój dydaktyki przedmiotu w Gdańskim Gimnazjum Akademickim do schyłku XVII w [Studien zur Geschichte des Geschichtsunterrichts: Entwicklung der Didaktik dieses Fachs im Danziger Akademischen Gymnasium am Ausgang des 17. Jh.]. Gdańsk 1973, S. 32; Bartosz Awianowicz: Rhetorische Argumentation in den Konstitutionen und Programmen der akademischen Gymnasien in Danzig und Thorn von 1568 bis 1658. In: Liliana Lewandowska, Katarzyna Szczerbowska-Prusevicius, Włodzimierz Zientara (Hg.): Vergangenes in Er- 
zum Beispiel im ersten Band 1586 Johann Sturms Schriften, während die Bände der Folgejahre Schulprogramme sowie humanistische Texte zur Rhetorik, Stilistik und Grammatik beinhalteten. ${ }^{8}$ Diese Publikation deutet auf zwei Faktoren hin, die für die Thorner Presselandschaft konstitutiv waren, nämlich einerseits auf das Patronat der städtischen Obrigkeiten sowie andererseits auf die Möglichkeiten, welche die Nähe der Schule mit seiner Druckerei und seiner Bibliothek mit sich brachte. ${ }^{9}$ Von der Stadtund zugleich Gymnasialdruckerei war bereits in den Vorworten zum genannten Jahrbuch die Rede, ${ }^{10}$ weil diese erst mithilfe Heinrich Strobands gedeihen konnte. ${ }^{11}$ Zugleich jedoch wurde deren Tätigkeit den Verfügungen und der Zensur des Stadtrates und der Scholarchen unterstellt, was einen unverkennbaren Einfluss auf die Thorner Zeitschriften haben sollte.

Die Blüte der Thorner Schule unter der Schutzherrschaft Heinrich Strobands trug auch zu einem Wandel bei, der sich in den Gelehrtenkreisen der Stadt vollzog. Verbesserte Bedingungen, wie die Renovierung der Gebäude des Franziskanerklosters als Sitz des Gymnasiums, die Errichtung einer Bibliothek und der Bau der Oeconomia, eines Internats für bedürftige Schüler, sowie die Sorge für das Gehalt der Professoren, zogen nicht nur neue Studenten und Lehrkräfte nach Thorn. Sie ermöglichten auch die Herausbildung einer wissens- und kulturhungrigen oberen Schicht, die meistens ein Studium in Krakau (Kraków), Königsberg (Kaliningrad), Wittenberg oder Leipzig absolviert hatte und nun sowohl an der Produktion als auch an der Rezeption von Kulturerzeugnissen beteiligt war, die im Umfeld der Schule entstanden. ${ }^{12}$ Auf diese Entwicklungen, die von der (damals vornehmlich calvinistischen) Elite getragen wurden, wirkten sich bald jedoch konfessionelle Streitigkeiten hemmend aus, die mit Geistlichen wie Franz Burchardi, Benedictus Morgenstern oder Simon Musaeus in die Stadt gelangten. ${ }^{13}$ Der Einzug lutherischer Orthodoxie in das Gymnasium bedeutete

innerung rufen... Beiträge zur Kulturgeschichte des Königlichen Preußen. Berlin 2014, S. 25-32, hier S. 30 .

8 Vgl. Institutionis literatae sive de discendi atque docendi ratione tomus primus, Sturmianus. Thorn 1586; Institutionis literatae, sive de discendi atque docendi ratione tomus secundus. Thorn 1587; Institutionis literatae, sive de discendi atque docendi ratione tomus tertius, quo qui libelli contineatur, proxime sequens pagella docebit. Thorn 1588. Eine Inhaltsangabe findet sich in: Stanisław Tync: Dzieje gimnazjum toruńskiego (1568-1793) [Geschichte des Thorner Gymnasiums (1568-1793)]. In: Roczniki Towarzystwa Naukowego w Toruniu 34 (1927), S. 55-284, hier S. $149 f$.

9 Vgl. zum zweiten Aspekt Zygmunt Mocarski: Książka w Toruniu do roku 1793. Zarys dziejów [Buchgeschichte in Thorn bis 1793]. Toruń 1934, S. 51.

10 Vgl. Institutionis literatae. Bd. I. (wie Anm. 8), S. xiija; Institutionis literatae. Bd. II (wie Anm. 8), S. xijb.

11 Vgl. Janina Huppenthal: 400 lat drukarstwa w Toruniu (Część I: XVI-XVIII w.) [400 Jahre der Buchdruckkunst in Thorn (Teil I: 16.-18. Jh.)]. In: Rocznik Toruński 4 (1970), S. 251-277, hier S. 254; Mocarski, Książka w Toruniu (wie Anm. 9), S. 27.

12 Vgl. Salmonowicz, Kultura umysłowa Torunia (wie Anm. 5), S. $213 \mathrm{f}$.

13 Vgl. ebd., S. 218f.; Tadeusz Glemma: Stosunki kościelne w Toruniu w stuleciu XVI i XVII na tle dziejów kościelnych Prus Królewskich [Konfessionelle Beziehungen in Thorn des 16. und 17. Jh. vor dem Hintergrund der Kirchengeschichte des Königlichen Preußen]. Toruń 1934, S. 90. 
jedoch nicht das Ende des regen Kulturlebens der Weichselstadt, obwohl sich ein langsamer Verfall bemerkbar machte. Öffentliche Disputationen, Theateraufführungen $^{14}$ und die Publikationstätigkeit der Druckerei, die in ein Unternehmen des Stadtrates umgewandelt wurde, waren in der Stadt stets präsent. Einen zusätzlichen Ansporn für die protestantischen Gelehrten bildete das 1605 gegründete Jesuitenkollegium, ${ }^{15}$ dessen Erziehungs- und Publikationstätigkeit den städtischen Obrigkeiten ein Dorn im Auge war. ${ }^{16}$ Mehrmals kam es in den Jahren 1606, 1614 und erneut 1688 zu antikatholischen Unruhen, auch die Anwesenheit der Schweden in der Stadt wurde von den damals bereits vorwiegend lutherischen Obrigkeiten für ihre antikatholischen Zwecke instrumentalisiert. ${ }^{17}$

Während der Kriege Polen-Litauens gegen Schweden in den 1620er und 1650er Jahren konnte zwar ein Zuwachs an polemischem Schrifttum, vornehmlich an Flugblättern und Flugschriften, verzeichnet werden, doch auf die Wirtschaft und folglich auch das Kulturleben Thorns hatten die kriegerischen Auseinandersetzungen einen negativen Einfluss. Nicht minder wichtig waren die mit ihnen einhergehenden konfessionellen Konflikte. ${ }^{18}$ Als ein wichtiges Handelszentrum zog Thorn auch in Kriegszeiten zahlreiche Zuwanderer an, wobei sich darunter nur wenige Gelehrte, Gymnasialschüler und Handwerkslehrlinge befanden, während die Mehrzahl Dienstpersonal und städtische Randgruppen ausmachten. Diese vornehmlich polnischsprachigen und katholischen Bevölkerungsteile, die in den Vorstädten lebten, leisteten keinen Beitrag zum städtischen Geistesleben, machten aber die Präsenz von etwas Andersartigem und Fremdem spürbar. Ihre geringe Möglichkeit des sozialen Aufstiegs, die mit der ethnischen Zugehörigkeit und der Konfession verschränkt war, machte sie zu einer zwar stummen, aber in der Stadt durchaus präsenten Gruppe. Diese Zuwanderung konnte die Verluste der aufeinanderfolgenden Seuchen - 1600, 1602, 1624-1625, 1629-1630, 1656, 1660 - zwar rein zahlenmäßig ausgleichen. Der dadurch forcierte konfessionelle Wandel im Stadtgefüge führte aber auch zu einer

14 Vgl. Bronisław Nadolski: Teatr szkolny gimnazjum toruńskiego w XVII i XVIII wieku [Das Schultheater des Thorner Gymnasiums im 17. und 18. Jh.]. In: Zeszyty Naukowe Uniwersytetu Mikołaja Kopernika w Toruniu 17 (1966), S. 118-157.

15 Vgl. Stanisław Salmonowicz: Szkoły jezuickie a gimnazja akademickie w Prusach Królewskich XVI-XVIII wieku. Próba porównania [Jesuitenschulen und Akademische Gymnasien im Königlichen Preußen des 16.-18. Jh. Vergleichende Betrachtung]. In: Rocznik Gdański 47/1 (1987), S. 151-166; Kazimierz Maliszewski, Waldemar Rozynkowski (Hg.): Jezuici w Toruniu 1596-1996 [Jesuiten in Thorn]. Torun 1997; Liliana Górska: Religious Tensions in Early Modern Torun, a History of War and Peace? In: Bojan Borstner, Smiljana Gartner, Sabine Deschler-Erb, Charles Dalli, Iwan-Michelangelo D’Aprile (Hg.): Historicizing Religion. Critical Approaches to Contemporary Concerns. Pisa 2010, S. $103-119$.

16 Zugleich aber wurde das panegyrische Schrifttum der Thorner Jesuiten in der protestantischen Stadtdruckerei veröffentlicht, vgl. Salmonowicz, Kultura umysłowa Torunia (wie Anm. 5), S. 209, Anm. 65.

17 Vgl. Stanisław Salmonowicz: Szkice toruńskie z XVII-XVIII wieku [Thorner Skizzen aus dem 17.-18. Jh.]. Toruń 1992, S. 20.

18 Vgl. Salmonowicz, Kultura umysłowa Torunia (wie Anm. 5), S. 204. 
Polarisierung und (zugleich auch politischen) Radikalisierung der Bürgerschaft. ${ }^{19}$ Für die zweite Hälfe des 16. Jahrhunderts wird die Bevölkerungszahl Thorns auf ungefähr 12.000 geschätzt, ${ }^{20}$ während die intellektuelle Elite etwa 40 Personen umfasste. ${ }^{21}$ Hundert Jahre später belief sich diese bereits auf 150 bis 200 Familien. ${ }^{22}$

\section{Gelehrtes Leben im Thorn des 18. Jahrhunderts}

Der Anfang des 18. Jahrhunderts brachte nicht nur Krieg, Durchmärsche und die Anwesenheit polnischer, litauischer und russischer Truppen in der Stadt mit sich. ${ }^{23}$ Insbesondere erneute Massenerkrankungen (1708-1710, vor allem im städtischen Umland) sorgten dafür, dass die Bevölkerungszahl von 12.000 vor dem Nordischen Krieg auf ungefähr 9.000 sank. ${ }^{24}$ Lutherische Zuwanderung aus dem Reich trug zum langsamen Wiederaufbau des Thorner Patriziats bei, so dass in den 1720er Jahren von ungefähr 850 bis 900 am Kulturleben der Stadt beteiligten Einwohnern die Rede sein konnte. ${ }^{25}$ Anfang des 18. Jahrhunderts bildeten die Lutheraner die Mehrheit der Bewohner Thorns, die wenigen calvinistischen Familien nahmen inzwischen nur noch selten am politischen Leben der Stadt teil. ${ }^{26}$ Zugleich drang langsam pietistisches Denken nach Thorn, vor allem in das Akademische Gymnasium.

Am Gymnasium finden sich auch erste Spuren der (Früh-)Aufklärung in der Stadt. Bereits im 17. Jahrhundert lassen sich die Gymnasialprofessoren Heinrich Schaeve, ${ }^{27}$

19 Vgl. Stefan Cackowski: Terytorium, ludność, władze miejskie [Territorium, Bevölkerung, Stadtbehörden]. In: Biskup (Hg.), Historia Torunia (wie Anm. 5), S. 7-47, hier S. $19 \mathrm{f}$.

20 Vgl. Marian Biskup, Lucjan Koc: Prusy Królewskie w drugiej połowie XVI w. [Das Königliche Preußen in der zweiten Hälfte des 17. Jh.]. Warszawa 1961, S. 67-74.

21 Vgl. Salmonowicz, Kultura umysłowa Torunia (wie Anm. 5), S. 213.

22 Vgl. ebd., S. 226.

23 Vgl. Jarosław Poraziński: Oblężenie Torunia w 1703 roku. Uwagi i refleksje w związku z 300 rocznicą [Die Belagerung Thorns 1703. Anmerkungen und Überlegungen anlässlich ihres 300. Jahrestages]. In: Rocznik Toruński 30 (2003), S. 65-84.

24 Vgl. den zeitgenössischen Bericht von Jacob Henrich Zernecke: Das verpestete Thorn oder summarischer Auszug der Pestilentz-Seuchen [...]. Thorn 1710 sowie Stanisław Salmonowicz: Toruń wobec zarazy w XVII i XVIII wieku [Thorn und die Seuchen im 17. und 18. Jh.]. In: Rocznik Toruński 16 (1983), S. $241-256$.

25 Vgl. Stanisław Salmonowicz: Myśl Oświecenia w Toruniu [Aufklärung in Thorn]. Toruń 1982, S. 12. 26 Vgl. als zeitgenössische Situationsaufnahme: Ignatius Bohuslav: Polonia reformata oder Zuverlässige Nachricht von denen Evangelisch-Reformierten Kirchen. Berlin 1754. Ferner zu den genannten Entwicklungen in allen drei großen königlich-preußischen Städten: Michael G. Müller: Zweite Reformation und städtische Autonomie im Königlichen Preußen. Danzig, Elbing und Thorn in der Epoche der Konfessionalisierung (1557-1660). Berlin 1997, S. 138-165.

27 Vgl. Salmonowicz, Myśl Oświecenia w Toruniu (wie Anm. 25), S. 20 f. 
Johann Meier, ${ }^{28}$ Georg Seger ${ }^{29}$ und um die Jahrhundertwende Paul Pater und Johann Sartorius $^{30}$ als Anhänger des Kartesianismus und Heliozentrismus, als innovative Mediziner (Seger führte als erster Autopsien in Thorn durch) und Mathematiker sowie als Lehrer erkennen, die in Anlehnung an Jan Amos Komenský (Johann Amos Comenius) ihren Schülern nicht nur reine Theorie vermittelten, sondern auch anhand von Beispielen lehrten. Paul Pater entwickelte selbst Hilfsmittel für den Unterricht. Neben innovativen Lehrmethoden verbanden ihn das Interesse für die Buchdruckkunst, die Nähe zum Pietismus sowie Konflikte mit den kirchlichen und städtischen Obrigkeiten mit den anderen Frühaufklärern in Thorn. ${ }^{31}$ Die Berufung Peter Jaenichens $^{32}$ zum Rektor des Gymnasiums zu Thorn 1706 hatte den Einzug zahlreicher Erneuerer sowohl in wissenschaftlicher als auch in konfessioneller Hinsicht in Schule und Stadt zur Folge (Reinhold Friedrich Bornmann, Georg Peter Schultz, Johann Friedrich Bachstrom, Johann Arndt). In ihren Vorlesungen wurden Werke von René Descartes, Baruch Spinoza, Gottfried Wilhelm Leibniz, Christian Wolff und John Locke behandelt, lange bevor sie die Schulen Warschaus erreichten.

Ein solches Denken, begleitet vom Bekenntnis der Professoren Bachstrom und Bornmann zum Pietismus, stieß auf Proteste der örtlichen Pfarrer. ${ }^{33}$ Während Bachstrom wegen seiner Auftritte Thorn verlassen musste, konnte sich Bornmann gegen seine Gegner meistens erfolgreich durchsetzten. Von seinen Interessen zeugt die Inaugurationsrede Quantum Mathematici Nicolao Thorunesi debeant. Der sich zur Empörung der örtlichen Pfarrerschaft vom Leben der protestantischen Gemeinde fernhaltende Bornmann zählte zu den aktivsten Anhängern von Nikolaus Kopernikus in der Region und war auch für die Einführung von Newtons Philosophiae naturalis principia mathematica in den Gymnasialunterricht verantwortlich. Eine breit kommentierte Debatte löste seine Disputatio philosophica de pluralitate mundorum aus, in der er zu beweisen

28 Vgl. Stanisław Salmonowicz: Jan Meyer (Meier, Mayer). In: Stanisław Gierszewski, Zbigniew Nowak (Hg.): Słownik Biograficzny Pomorza Nadwiślańskiego [Biographisches Wörterbuch von Weichselpommern]. Bd. 3. Gdańsk 1997, S. $192 \mathrm{f}$.

29 Vgl. Aleksander Drygas: Jerzy Seger. In: Gierszewski/Nowak (Hg.), Słownik Biograficzny Pomorza Nadwiślańskiego (wie Anm. 28). Bd. 4 (1997), S. 315f.; Marian Łysiak: Doktor medycyny i filozofii Georg Seger (1629-1678) [Doktor der Medizin und Philosophie Georg Seger (1629-1678)]. Toruń 2015.

30 Vgl. Stanisław Salmonowicz: Profesor Jan Sartorius (1656-1729). Z dziejów filozofii eklektycznej w Prusach Królewskich [Professor Johann Sartorius (1656-1729). Aus der Geschichte der eklektischen Philosophie in Königlich-Preußen]. In: Jerzy Trzoska (Hg.): Strefa Bałtycka w XVI-XVIII w. Polityka Społeczeństwo - Gospodarka [Die Ostsee im 16-18. Jh. Politik - Gesellschaft - Wirtschaft]. Gdańsk 1993, S. 183-196; Włodzimierz Zientara: Jan Sartorius. In: Gierszewski/Nowak (Hg.), Słownik Biograficzny Pomorza Nadwiślańskiego (wie Anm. 28). Bd. 4 (1997), S. 147 f.

$31 \mathrm{Zu}$ Paters Leben und Schriften mit einem detaillierten Verzeichnis seiner Werke sowie Forschungsliteratur vgl. Klaus-Dieter Herbst, unter Zuarbeit von Anna Mikołajewska: Paul Pater. In: Biobibliographisches Handbuch der Kalendermacher von 1550 - 1750 (13.11.2017). URL: https://www. presseforschung.uni-bremen.de/dokuwiki/doku.php?id=pater_paul (26.03.2020).

32 Vgl. Stanisław Salmonowicz: Peter Jaenichen. In: Gierszewski/Nowak (Hg.), Słownik Biograficzny Pomorza Nadwiślańskiego (wie Anm. 28). Bd. 2 (1994), S. 259.

33 Vgl. Salmonowicz, Myśl Oświecenia w Toruniu (wie Anm. 25), S. 28 f. 
versuchte, dass sich die Hypothese von der Vielheit der Welten durchaus mit der Lehre der Kirche vereinbaren ließe - nämlich durch die allegorische Auslegung der Heiligen Schrift. ${ }^{34}$ Ihr Finale fand diese Auseinandersetzung in der ersten Thorner gelehrten Zeitschrift, dem Gelahrten Preussen, in der sich Georg Peter Schultz auf die Seite seines Freundes Bornmann schlug und eine bissige Antwort von Paul Dalcke, dem Schüler des Seniors vom lutherischen Ministerium Ephraim Praetorius, publiziert wurde. ${ }^{35}$

\section{Das Gelahrte Preussen (1722-1725)}

Das Gelahrte Preussen erschien, wenn man seine Fortsetzung, das Continuierte Gelehrte Preussen miteinbezieht, von 1722 bis 1725 in deutscher und (seltener) in lateinischer Sprache im Oktavformat in Thorn. ${ }^{36}$ Es wurde zum Sprachrohr des gelehrten Diskurses sowohl im Königlichen als auch im Herzoglichen Preußen. Der Preis blieb über diese Zeit konstant, bis 1725 bestand die Möglichkeit der Pränumeration, erst 1725 war ,jedes Quartal besonders mit baaren Gelde zubezahlen““. ${ }^{37}$ Der Redakteur Georg Peter Schultz (1680 - 1748) war Sohn des Rektors der Universität in Frankfurt an der Oder und hatte Jura, Philosophie und Medizin sowohl an dieser Hochschule als auch an der Universität Leipzig studiert. Nach kurzen Lehrtätigkeiten an der Universität seiner Heimatstadt und an der Ritterakademie zu Berlin sowie nach einer Studienreise über Helmstedt, Bremen, Hamburg, Groningen, Amsterdam, Rotterdam und Utrecht nach Leiden war er 1711 zum Konrektor an das Thorner Akademische Gymnasium berufen worden, wo er als Organisator von Lernprozessen Nachdruck auf praktisches, zweckgerichtetes Wissen legte. ${ }^{38}$

34 Vgl. ebd.; ders.: Pietyzm w dawnym Toruniu [Pietismus im alten Thorn]. In: Rocznik Toruński 13 (1978), S. 185-198, hier S. 189-191.

35 Vgl. Das Gelahrte Preussen. Teil II. 14ter Bogen (1723), S. 218f. sowie Teil III (März 1724), S. 400 f. (beigefügt Dalckes Rechtmäßige Vertheidigung).

36 Sowohl Das Gelahrte Preussen [im Folgenden: GP] als auch das Continuierte Gelehrte Preussen [im Folgenden: CGP] sind als Digitalisate in der e-Bibliothek von Kujawien-Pommern zu finden (URL: https://kpbc.umk.pl/dlibra/publication/8487?tab=1\#structure [10.04.2020]). Der vollständige Titel lautete: Das Gelahrte Preussen/ Aus Neuen und alten/gedruckten und ungedruckten/grossen und kleinen Schrifften/Wie auch Der gelahrten Männer/Welche In Preussen gebohren/ oder daselbst gelebet/ oder von Preußischen Sachen geschrieben/ Nahmen und Leben/ Wochentlich vorgestellet/ [...] bzw. Continuiertes Gelehrtes Preussen/ Oder Vierteljähriger Außzug aus allerhand Preußischen Büchern nebst der Gelehrten Männer Leben und MSC. Anmerckungen von Preußischen Denckwürdigkeiten/ [...].

37 Vorrede. In: CGP. Erstes Quartal (1725), o. S.

38 Vgl. Stanisław Salmonowicz: Wizerunek żywota Jerzego Piotra Schultza uczonego toruńskiego pierwszej połowy XVIII w. [Das Leben von Georg Peter Schultz]. In: Rocznik Toruński 12 (1977), S. $145-154$. 


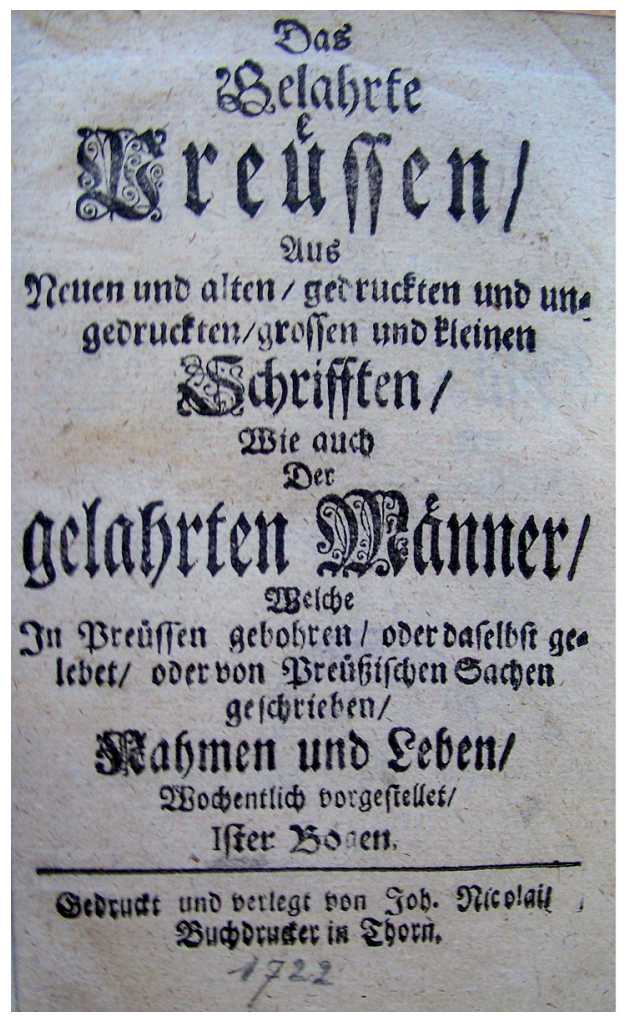

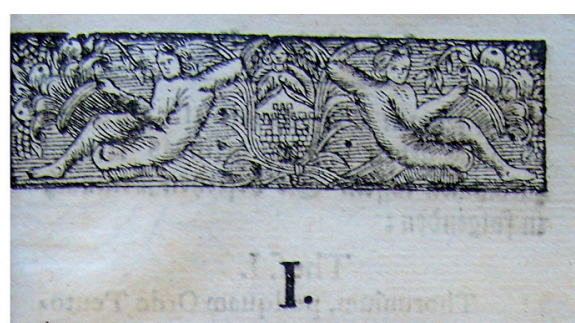

Conlectanea II.

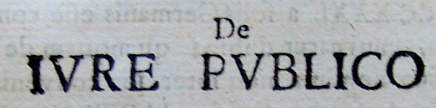

Civitatis Thorunienfis

Ordine Sub Teutonico.

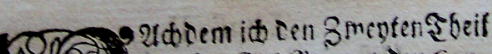
Ditjes (3)! ?ht. mit ten Con1. Po lectoners I. De verbis quibusdam folemibus Senatus Populique Thorunienfis an. gefangen uno toiftens tin Itinfftig bin mebrete Obfervationes de Me: morandis Thorunenfibus einjurtiden; als bofier es werde ier geneigte fefer aud

Abb. 1: Titelblatt des ersten Bogens des Gelahrten Preussen von 1722.

Abb. 2: Florale Vignette und Initiale des Gelahrten Preussen, Teil II vom April 1723, S. 1.

Sein Gelahrtes Preussen kam zwischen Oktober 1722 und März 1723 zunächst als Wochenschrift heraus. Es umfasste in diesem Halbjahr 24 Bögen, über die sich auch die Paginierung fortsetzte, mit arabischen Ziffern am oberen und Buchstaben am unteren Rand. Ab dem neunten Bogen wurde dem Inhalt des jeweiligen Bogens ein Inhaltsverzeichnis vorangestellt. ${ }^{39}$ Im zweiten Halbjahr zwischen April und August 1723 änderte sich der Untertitel. ${ }^{40}$ Für Inhaltsverzeichnisse der einzelnen Stücke (nicht mehr Bögen) war nun eine getrennte Seite vorgesehen, am oberen Rand wurden der Name des Autors des jeweiligen Beitrags und dessen Titel genannt. Seit diesem Teil II erschien die Zeitschrift monatlich, es wurden auch florale Vignetten (s. Abb. 2) und solche mit einem Engelkopf eingeführt. Zudem war es den Autoren möglich, ihrem eingesandten Beitrag einen Kupferstich beizufügen, wenn dieser unentbehrlich war.

39 Vgl. GP. 9ter Bogen (1722), S. 129.

40 Er lautete nun: Monathl. Außzug Aus Neuen und Alten/ gedruckten u. ungedruckten/ großen u. kleinen Preussischen Schriften/ Wobei auch einige Nachrichten Von der Gelahrten Männer/ Welche In Preussen gebohren/oder daselbst gelebet/ oder von Preussischen Sachen geschrieben Lebens-Läuffe und Bücher/ Mit eingemischten MSC. Anmerckungen von allerhand Preuß. Denckwürdigkeiten. 
Die Kosten sollten in solchen Fällen von der Redaktion getragen werden. ${ }^{41}$ Teile III (November 1723-März 1724) und IV (April 1724-September 1724) folgten in ihrer Ausgestaltung ihren Vorgängern. Nachdem den ersten drei Teilen jeweils ein unpaginiertes Personen- und Sachregister nachgestellt war, wurde im vierten Teil ein Register zu allen bisher erschienen Teilen abgedruckt. ${ }^{42}$

Im Sommer 1724 mündeten die angespannten konfessionellen Beziehungen in den so genannten Thorner Tumult, der die Redaktionsarbeit unterbrach. Schultz schrieb dazu: „Die Ursachen sind Weltkündig/ und kein vernünftiger Mann wird mich dringen solche alhier zu offenbaren/ und nahmhafft zu machen“. ${ }^{43}$ Unter dem Titel Continuiertes Gelehrtes Preussen erschien das Periodikum 1725 wieder, nun als Vierteljahresschrift und nur noch für ein Jahr. Ob die Konkurrenz seitens des Königsberger Erleuterten Preussen dazu beitrug, dass Schultz seine Publikationstätigkeit einstellte, gilt in der Forschung als naheliegend. ${ }^{44}$ Allerdings konnten sich dagegen die 1726 zum ersten Mal publizierten Meletemata Thorunensia des Thorner Rektors Jaenichen auf dem Markt insofern behaupten, als auch 1727 ein zweiter Band dieses Periodikums erschien. ${ }^{45}$ Nicht ganz unbegründet erscheint daher die Annahme, dass ein Medium, welches auch der Austragung von Auseinandersetzungen im Luthertum diente (wie zum Beispiel an der Debatte Bornmann-Dalcke-Praetorius deutlich wurde), in einer Zeit nicht weiter fortgesetzt werden konnte, in der es nach dem Tumult hieß, eine gemeinsame protestantische Front gegen den Katholizismus aufzubauen. Dabei beschäftigte sich die Schrift immer wieder auch intensiv mit der Stellung Preußens im polnisch-litauischen Staatswesen unter August II., was ihr Fortbestehen hätte sichern können.

Im Gelahrten Preussen sowie in seiner Fortsetzung im Jahr 1725 wurde ausschließlich über die preußische Gelehrtenrepublik publiziert. Es diente somit der Begründung einer allgemeinen preußischen Identität. Zwar überwogen die Beiträge, die auf westpreußische Angelegenheiten fokussiert waren, das Herzogtum wurde aber keineswegs ausgeschlossen. ${ }^{46}$ In seiner publizistischen Tätigkeit konnte sich Schultz

41 Vgl. Vorrede. In: GP. Teil II (30. April 1723), o. S.

42 Unter dem Titel: „Allgemeines Register über Die Schrifften/ Lebens-Läuffe/ MSC. Brieffe und Anmerckungen Gelehrter Männer/ welche In den Vier Theilen des Gelahrten Preussen enthalten sind“. 43 Vorrede. In: CGP. Erstes Quartal 1725.

44 Vgl. Mocarski, Książka w Toruniu (wie Anm. 9), S. 96.

45 Vgl. Maria Dunajówna: Pierwsze toruńskie czasopismo naukowe w XVIII wieku. „Das Gelahrte Preussen“ [Die erste gelehrte Zeitschrift Thorns im 18. Jh. „Das Gelahrte Preussen“]. In: Zbigniew Zdrójkowski (Hg.): Księga pamiątkowa 400-lecia Toruńskiego Gimnazjum Akademickiego [Festschrift zum 400-jährigen Bestehen des Thorner Akademischen Gymnasiums]. Bd. I: XVI-XVIIIw [16.-18. Jh.]. Toruń 1972, S. 241-272, hier S. 247.

46 Vgl. Axel E. Walter: Regionale Identitätskonzepte der ,ost-‘ und ,westpreußischen` Landeshistoriographie in den gelehrten Zeitschriften der 1720er Jahre. In: Joanna Kodzik, Włodzimierz Zientara (Hg.): Hybride Identitäten in den preußisch-polnischen Stadtkulturen der Aufklärung. Studien zur Aufklärungsdiffusion zwischen Stadt und Land, zur Identitätsbildung und zum Kulturaustausch in regionalen und internationalen Kommunikationsnetzwerken. Bremen 2016, S. 23-52, hier S. 28 -34. 
auf andere in Preußen erscheinende Produkte gelehrter Kommunikation stützen. Im Gelahrten Preussen und Continuierten Gelehrten Preussen wurde mehrmals auf zeitgenössische Periodika Bezug genommen. Den ersten Bogen im Jahr 1722 eröffnete beispielsweise eine Rezension der Polnischen Bibliothec, die später in zwei anderen Bögen fortgesetzt wurde. ${ }^{47}$ Im Juni 1723 stellte Schultz die „Neue [...] und lobenswürdige [...] Arbeit [...] M. Mich. Lilienthal“ vor, also das zum ersten Mal im Mai diesen Jahres erschienene Erleuterte Preußen seines Königsberger Kollegen. Dass die beiden Redakteure nicht nur ihre Arbeit gegenseitig aufmerksam verfolgten, sondern zugleich konkurrierten und zusammenarbeiteten, bezeugen eine Passage aus einem Brief Daniel Heinrich Arnoldts an Gottsched vom 9. Februar $1725^{48}$ sowie ein Beitrag zum Bernsteinvorkommen bei Thorn im Gelahrten Preussen im Juni 1723, dem im Oktober eine ähnliche Abhandlung im Erleuterten Preussen folgte, worauf wiederum die Thorner Monatsschrift im November mit einem Extract aus einem Schreiben vom gefundenen Bernstein unweit Thorn antwortete. ${ }^{49}$ Es finden sich im Thorner Blatt auch weitere Kommentare über Michael Lilienthals Arbeit, die Zeugnis einer intensiven wechselseitigen Rezeption sind, wie zum Beispiel jener zum Vergleich des polnischen Reichstags und der Frauenzimmer-Wäsche im Erleuterten Preussen ${ }^{50}$ oder Kurioses zum Leben der Hl. Dorothee, das „Herr Lilienthal [...] gantz und gar ungenennet gelassen". ${ }^{1}$

Auch die Schicksale der Königsberger Nova Publica Latina wurden in Thorn verfolgt. Nachdem in den Jahren 1722 und 1723 dem Periodikum Informationen zu Neuerscheinungen entnommen worden waren, ${ }^{52}$ informierte das Gelahrte Preussen im Januar 1724 darüber, dass „das von 1719. biß zum Ende des 1723sten Jahrs vollführte/ nützliche und galante, Institutum mit den Königsbergischen Lateinischen Zeitungen oder Novis Publicis nicht fernerhin wird continuiret werden“, und machte zugleich Werbung für dessen Nachfolger, die Historisch-geographisch und genealogischen An-

47 Vgl. GP. 1ster Bogen (1722), S. 5-16; GP. 5ter Bogen (1722), S. 68-82; GP. 19ter Bogen (1723), S. 292-301.

48 Vgl. Daniel Heinrich Arnoldt an Gottsched. Königsberg, 9. Februar 1725. In: Johann Christoph Gottsched: Briefwechsel. Historisch-kritische Ausgabe. Bd 1: 1722-1730. Hg.v. Detlef Döring, Franziska Menzel. Berlin 2007, S. $29 \mathrm{f}$.

49 Vgl. GP. Teil II (Juni 1723), S. 199-204; Erleutertes Preussen. Bd. I. 6. Stück, S. 393-416; GP. Teil II (November 1723), S. 139f. Beide Befunde bereits bei Walter, Regionale Identitätskonzepte (wie Anm. 46.), S. $46 \mathrm{f}$.

50 Vgl. GP. Teil III (Dezember 1723), S. 169. Weitere Zitate aus und Bezüge auf Erleutertes Preussen vgl. GP. Teil III (Februar 1724), S. 302-323; GP. Teil IV (Mai 1724), S. 80 -103; GP. Teil IV (September 1724), S. 311-317 sowie CGP. Drittes Quartal (1725), S. 42-72.

51 GP. Teil III (November 1723), S. 126.

52 Vgl. GP. Teil II (Mai 1723), S. 125-131; GP. Teil I, 14ter Bogen (1722), S. 220. 
merckungen. ${ }^{53}$ Rezipiert und exzerpiert wurden auch der Leipziger Neue Bücher-Saal sowie die Acta Eruditorum, die man zuweilen auch korrigierte. ${ }^{54}$

Materialbeschaffung für die Zeitschrift erfolgte durch Kontakte zu gelehrten Kollegen. Es sei hier wieder an Lilienthal erinnert, der Schultz Briefe von Johannes Zemelius und Martin Cyriacus zugeschickt haben soll, $;^{55}$ an den Elbinger Rektor Georg Daniel Seyler, der dem Redakteur den Entwurf seiner Abhandlung über polnische und preußische Münzen, die ungedruckte Poetische Beschreibung der Stadt Danzig Georg Gräblingers, die Vitae Episcoporum Varmiensium, Lebensläufe von Tiedemann Giese sowie Johann Zemelius zur Verfügung stellte; ${ }^{56}$ an den Marienburger Stadtsekretär Johann Wilhelm Weinreich, den Einsender des Lebenslaufs von Andreas Knöffel, ${ }^{57}$ sowie an zahlreiche andere Gelehrte aus Danzig (Gdańsk), ${ }^{58}$ Elbing (Elbląg), Königsberg, Marienwerder (Kwidzyn) und Kulm (Chełmno). ${ }^{59}$

Somit vermittelte das Thorner Blatt ein Gesamtbild der preußischen Gelehrtenrepublik, indem es landeskundliches und -geschichtliches sowie naturkundliches Schrifttum des Doppellandes Preußen verzeichnete, Lebensläufe und Werke sowohl königlicher als auch herzoglicher Preußen vorstellte und das gelehrte Treiben an den Gymnasien Danzigs und Thorns sowie an der Königsberger Albertina beschrieb (in den Rubriken Neues von gelehrten Sachen und Nova Literaria) ${ }^{60}$ Auch wenn Persönlichkeiten Polen-Litauens ins Gelahrte Preussen aufgenommen wurden, hob man immer ihren Bezug zu Preußen hervor. ${ }^{61}$ Nicht selten warb das Blatt für gelehrte Publikationen, informierte über Versteigerungen von Privatbibliotheken oder rief die Leserschaft dazu auf, verschollene bzw. handschriftliche Werke preußischer Gelehrter zu melden. ${ }^{62}$

53 GP. Teil III (Januar 1724), S. 243.Vgl. auch Stanisław Salmonowicz: Od Prus Książęcych do Królestwa Polskiego. Studia z dziejów prusko-pomorskich [Vom Herzoglichen Preußen bis zum Königreich Polen. Studien zur preußisch-pommerschen Geschichte]. Olsztyn 1992, S. 104 f.

54 Vgl. GP. Teil I. 22ster Bogen (6. März 1723), S. 340; GP. Teil II (Juni 1723), S. 192; CGP. Viertes Quartal (1725), S. 49-61; GP. Teil III (März 1724), S. 385.

55 Vgl. CGP. Drittes Quartal (1725), S. 1-21.

56 Vgl. GP. Teil I (30. Januar 1723), S. 271-279; GP. Teil III (November 1723), S. 79; GP. Teil III (Januar 1724), S. 214-236; GP. Teil IV (April 1724), S. 30 -54.; CGP. Drittes Quartal (1725), S. $22-37$.

57 Vgl. GP. Teil II (30. April 1723), S. 41.

58 Zu Danzigs Rolle als „Knotenpunkt der Gelehrsamkeit“ vgl. den Beitrag von Marc Banditt in dieser Themenausgabe.

59 Vgl. Dunajówna, Pierwsze toruńskie czasopismo naukowe (wie Anm. 45), S. 248 f.

60 Vgl. Dissertationen und Disputationen in Danzig und Thorn u. a. in GP. 12ter Bogen (1722), S. 200 - 212 (hier auch Gedächtnistag des Wohltäters des Thorner Gymnasiums Gottfried Krives); GP. Teil II (Mai 1723), S. 125-131; GP. Teil III (Oktober 1723), S. 55-60. Zur Albertina vgl. z. B. GP. 10ter Bogen (1722), S. 152-155; GP. 11ter Bogen (1722), S. 169; GP. Teil II (Mai 1723), S. 125-131.

61 Z. B. Andreas Załuskis Tätigkeit als ermländischer Bischof. In: GP. 6ster Bogen (1722), S. 94.

62 Vgl. z.B. die Meldung vom baldigen Erscheinen des zweiten Bandes von Lengnichs Geschichte der Preußischen Lande sowie von der Möglichkeit, den zweiten Band der Chronik Schütz' günstig zu pränummerieren (GP. 9ter Bogen [1722], S. 140f.); die Mitteilung, dass der Elbinger Buchhändler Bannehr Einzahlungen von 2 Poln. Gulden erbitte, um Brauns De Scriptorum Poloniae et Prussiae 
Das Bedürfnis des Redakteurs, alles Gelehrte und Kuriose aus beiden Teilen Preußens zu bewahren, kann leicht als barocke Sammelwut, Neigung zur Universalität und Polyhistorie abgetan werden. Es muss jedoch auch als eine Haltung wahrgenommen werden, die sich aus einer bestimmten sozio-politischen Situation nährte. Zudem räsonnierte der Redakteur des Periodikums mehrmals darüber, was es eigentlich bedeute, zusammenzufassen und zu rezensieren. Schon in der Vorrede, die dem ersten Bogen vorangestellt war, konstatierte er, „daß man die Schriften [im Gelahrten Preussen, Anm. der Vf.] recensiren/ aber nicht censiren/ und in Erzehlung der gelehrten Männer Lebens-Läuffe nicht sowohl des Lobens/ als der Wahrheit und Kürtze/ eingedenck sehn will.“63 Im Jahrgang 1722 überwogen noch Zusammenfassungen von Werken ohne Stellungnahme des Redakteurs sowie reine Auflistungen von bekannten Informationen. ${ }^{64}$ Ab August 1723 wurden die angeführten Schriften mit wachsendem Scharfsinn rezensiert, indem Sachfehler aufgelistet und berichtigt, falsche Datierungen, Verwechslungen von Namen und falsche Zuschreibungen der Autorschaft aufgespürt wurden. ${ }^{65}$ Es muss dabei daran erinnert werden, dass die Rezensionspraxis in gelehrten Zeitschriften zu dieser Zeit noch nicht einem Katalog fertiger Regeln folgte, sondern erst herausgearbeitet wurde. ${ }^{66}$

Das 1725 eingestellte Gelahrte Preussen versuchte zwar im Hinblick auf die in der Gegenwart ausgetragenen konfessionellen und politischen Konflikte seine Neutralität $\mathrm{zu}$ bewahren, doch die Sympathien des Redakteurs konnte man nicht immer ganz verbergen. So neigte Schultz wohl mehr der Gedankenführung des Thorner Schreibers Johann Sachs gegen den Helmstedter Rechtshistoriker Hermann Conring in De Scopo Reipublicae Polonicae, adversus Hermannum Conringium zu. ${ }^{67}$ Conrings Thesen von der Abhängigkeit des mittelalterlichen Polen vom Reich sowie dessen Argumentation für den schwedischen Einsatz in Polen-Litauen lehnte er ebenso ab wie seine Kritik an den vermeintlich anarchischen Zügen der polnischen Verfassung. ${ }^{68}$ Er erlaubte sich

drucken zu können (GP. 14ter Bogen [1722], S. 212); die Bitte um Nachricht zu verschollenen Schriften Böhms (GP. Teil II [Juni 1723], S. 192-199) sowie Schultz' Hinweis auf sein eigenes Werk, die Marchia Brandenburgica Docta (GP. Teil II [30. April 1723], S. 37-40.

63 Vorrede. In: GP. 1ster Bogen (1722), o. S.

64 Vgl. z. B. GP. 1ter Bogen (1722), S. 5-16 (Lengnichs Polnische Bibliothec); GP. 2ter Bogen (1722), S. 17-22 (Jeroschins Chronicon Prussiae).

65 Vgl. GP. Teil II (August 1723), S. 307-315; GP. Teil III (März 1724), S. 385-395 sowie 400 f.

66 Vgl. Katarzyna Chlewicka: „Es ist eben so gefährlich ein Schriftsteller als ein Journalist zu werden.“ Über die Maßstäbe angemessenen Rezensierens in den „Thornischen Nachrichten von gelehrten Sachen“ (1762-1766). In: Kodzik/Zientara (Hg.), Hybride Identitäten (wie Anm. 46), S. 215-226.

67 Vgl. GP. 7ter Bogen (1722), S. 118f.; Franciscus Marinius (Pseudonym von Johann Sachs, Anm. der Vf.): De Scopo Reipublicae Polonicae, adversus Hermannum Conringium, Professorem Helmstadiensem, Dissertatio qua simul Status Regni Poloniae novissime describitur. Breslau 1665. Vgl. dazu auch Dunajówna, Pierwsze toruńskie czasopismo naukowe (wie Anm. 45), S. $253 \mathrm{f}$.

68 Vgl. Hans-Jürgen Bömelburg: Polen und die deutsche Nation. Konfligierende Identitätszuschreibungen und antagonistische Entwürfe politischer Ordnung. In: Georg Schmidt (Hg.): Die deutsche Nation im frühneuzeitlichen Europa. Politische Ordnung und kulturelle Identität? München 2010, S. 129-156, hier S. 146-154. 
bissige Worte gegenüber Paul Dalcke, der, vom Thorner lutherischen Senior Ephraim Praetorius angespornt, gegen Reinhold Bornmanns Thesen polemisierte. ${ }^{69}$ Dass man im Thorner Blatt Praetorius nach seinem Tod ehrte, ${ }^{70}$ ändert wohl wenig an der gegen ihn gerichteten Rezensionstätigkeit von Schultz.

\section{Der Preußische Todes-Tempel (1728-1730)}

Bereits am Gelahrten Preussen konnte beobachtet werden, dass hier zum einen eine Entwicklung in Richtung Kritik und Rezension anstelle bloßer Zusammenfassungen stattfand und zum anderen Versuche unternommen wurden, das Blatt in seiner Ausgestaltung und Darbietung der Inhalte leserfreundlicher zu gestalten. Der experimentierfreudige Schultz kehrte bald mit einem neuen Periodikum auf den preußischen Zeitschriftenmarkt zurück, und zwar mit dem Preußischen Todes-Tempel, der in den Jahren 1728-1730 unregelmäßig erschien (wohl ungefähr alle zwei Monate, denn es kamen insgesamt 14 Hefte heraus). ${ }^{71}$ Es handelte sich hierbei um eine Schrift im Quartformat mit inszenierten Unterredungen zwischen Gelehrten und Gestalten aus der preußischen Geschichte (zum Charakter und Genre des Totengesprächs siehe unten mehr). ${ }^{72}$ Die einzelnen Beiträge unterschieden sich voneinander in der Schriftart mit Schmuckbuchstaben am Anfang und oft auch einer Vignette am Ausgang eines jeden Heftes (s. Abb. 4).

69 Vgl. GP. Teil IV (März 1724), S. 400 f.: Schulz habe sich entschieden, „[d]amit der Autor [Dalcke, Anm. der Vf.] nicht wiederumb Gelegenheit erzwingen möge sich durch Aergerniß an seiner Gesundheit zuschaden/ der glaube/ daß man ihn prostituiret/ wenn man seine Schrift nicht würdig geschätzet hätte inter nova Literaria Prussica zu referiren [...].“ Vgl. auch Salmonowicz, Myśl Oświecenia w Toruniu (wie Anm. 25), S. 42-44.

70 Vgl. GP. 22ster Bogen (6. März 1723), S. 338.

71 Ein Digitalisat des Preußischen Todes-Tempels [im Folgenden: PTT] kann auf Google Books eingesehen und heruntergeladen werden (URL: https://books.google.de/books?id=mEdiAAAAcAAJ\&hl= de\&num=10 [15.04.2020]). Der vollständige Titel lautete: Preußischer Todes-Tempel/ Worin/ Verstorbene Personen allerhand Standes/Von den außerlesensten Sachen/ Der Preußischen, Pohlnischen, Schwedischen und Brandenburgischen/ Geistlich-Weltlich- und Gelehrten Historie,/Geographie, und Stats-Rechts,/ Wie auch/ Neuen gelehrten Schriften in Preussen und Pohlen,/ Mit einander redende vorgesellet werden.

72 Vgl. Erste und zweite Unterredung: Hochmeister des Dt. Ordens Hermann von Salza und Königsberger Professor Johann Jacob Rohde; dritte Unterredung: Hochmeister Siegfried von Feuchtwangen und Gottlieb Schelwig, Professor am Danziger Gymnasium; 4. Unterredung: Albrecht I. und Abraham Calov; 5. Unterredung: Friedrich Wilhelm der Große und Simon Dach; 6. Unterredung: Albrecht I. und Abraham Calov; 7. Unterredung: Friedrich Wilhelm und Simon Dach; 8. Unterredung: Albrecht I und Abraham Calov; 9. Unterredung: Friedrich Wilhelm und Simon Dach; 10. Unterredung: Siegfried von Feuchtwangen und Gottlieb Schelwig; 11. Unterredung: poln. König Kasimir IV. und Philipp Cluver; 12. Unterredung: Albrecht I und Abraham Calov; 13. Unterredung: Siegfried von Feuchtwangen und Gottlieb Schelwig; 14. Unterredung: Kasimir IV. und Philipp Cluver. 

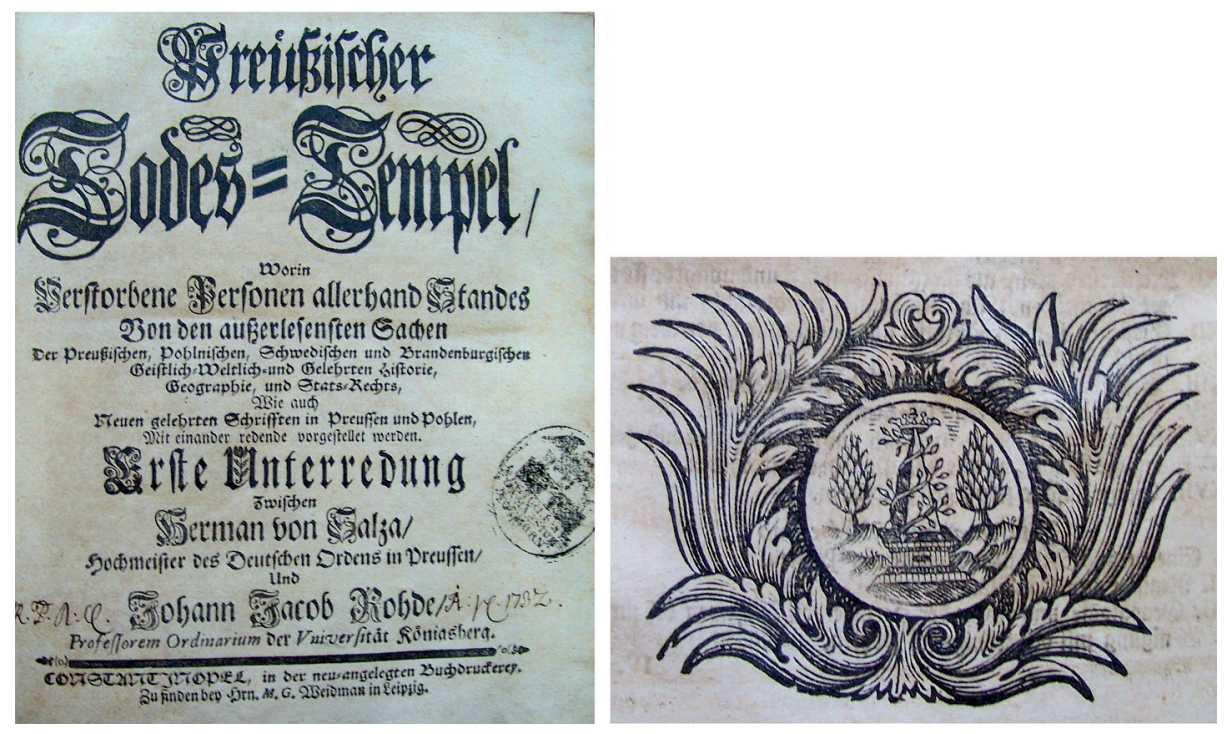

Abb. 3: Titelblatt der Ersten Unterredung des Preußischen Todes-Tempels von 1728.

Abb. 4: Vignette auf der letzten Seite der ersten Unterredung des Preußischen Todes-Tempels von 1728, unpag. (S. 62).

Die Paginierung wurde in allen Blättern fortlaufend fortgesetzt, mit arabischen Ziffern am oberen Rand und Buchstaben am unteren Rand sowie dem Titel der Zeitschrift am oberen Rand, ähnlich wie schon im Falle des Gelahrten Preussen. Ab dem dritten Heft wurde der Unterredung ein Inhaltsverzeichnis vorangestellt; später wurde es am Heftende angehängt. Ein Heft umfasste 36 bis 43 Seiten eines Totengesprächs und die wiederkehrende Rubrik „Mercurius“ von 9 bis 32 Seiten. Diese bestand aus Briefen, Reden, Dichtung mit oder ohne Kommentar des Redakteurs, die das Totengespräch ergänzten oder auch vom aktuellen politischen oder gelehrten Geschehen berichteten; auch auf Inhalte des Gelahrten Preussen wurde Bezug genommen. ${ }^{73}$ Wie schon in der Vorläufer-Zeitschrift wurden auch im Mercurius-Teil des Todes-Tempels Leben und Schriften von preußischen Gelehrten dargeboten. Man scheute nicht einmal vor Erzeugnissen der Gesellschaft Jesu zurück, in denen Heiligenverehrung und Wundergeschichten vorkamen. ${ }^{74}$ Die Aktualität dieser Rubrik wurde von neuesten politischen Nachrichten garantiert, die anfänglich die Form offizieller Schreiben besaßen und nur sehr knapp von der Redaktion kommentiert wurden, z. B. mit Bezug auf den Thorner Tumult in der dritten Unterredung. ${ }^{75} \mathrm{Ab}$ der siebten Unterredung verwandelte sich der Mercurius-Teil immer mehr in eine Rubrik mit überwiegend politischen Nachrichten, die mit Titeln wie „Aus Pohlen“ oder „Vom Kayserlichen Hofe“ eingeführt wurden. ${ }^{76}$

73 Vgl. z. B. PTT. Erste Unterredung (1728), S. 58.

74 Vgl. ebd., S. $56 \mathrm{f}$.

75 Vgl. PTT. Dritte Unterredung (1728), S. 197-203.

76 Vgl. PTT. Siebte Unterredung (1729), S. $461 \mathrm{f}$. 
Vielleicht war die erhitzte Rezeptionsgeschichte seiner ersten Zeitschrift der Grund dafür, dass sich Schultz im Todes-Tempel von heftigerer Kritik fernhielt, seinen Namen nicht nannte und auch als Erscheinungsort Konstantinopel statt Thorn angab. Die vierzehn Unterredungen sollten wohl ein relativ geschlossenes Ganzes darstellen, denn es wurde ihnen ein Sach- und Personenregister zum gesamten Todes-Tempel nachgestellt. Anscheinend war aber ursprünglich eine Fortsetzung geplant, weil im letzten Heft noch eine Rezension der Concordia Rationis et Fidei angekündigt wurde. ${ }^{77}$

Das seit der Antike bekannte Genre des Totengesprächs sollte oft als Tarnung für Satire und politische Kommentare dienen, aber auch eine verständige und klare Darbietung von gelehrten oder komplizierten Inhalten ermöglichen, so dass diese auch außerhalb der Gelehrtenrepublik verstanden werden konnten. ${ }^{78}$ Während also die Thematik sowohl des Gelahrten Preussen als auch des Todes-Tempels keine großen Unterschiede aufwies, deutete das 1728 von Schultz neu verwendete Genre auf den Versuch, größere Freiheit im engen Gefüge von politischen und konfessionellen Interessen, denen seine Publikationstätigkeit ausgesetzt war, zu erlangen. ${ }^{79}$ Es handelte sich hierbei nicht unbedingt nur um das angespannte Klima in Thorn nach dem Tumult von 1724, sondern vielleicht noch mehr um die Stellung des Königlichen Preußen im polnisch-litauischen Staatsverband angesichts einer auf Beschneidung des preußischen Partikularismus und der Religionsfreiheiten ausgerichteten Politik. Sowohl im Gelahrten Preussen als auch im Preußischen Todes-Tempel und seinem nächsten Presseprodukt Neues der Welt wandte sich Schultz nicht nur an eine gelehrte Leserschaft, sondern zum Teil auch an ein Publikum, das des Lateinschen nicht mächtig war. Seine Arbeit sollte ausdrücklich auch „[u]mb derer willen [...], die das Latein nicht verstehen“ geschehen, die in seinen Zusammenfassungen bzw. Rezensionen vom Inhalt lateinischer Texte erfahren sollten. ${ }^{80}$ Oft wurden Originaldokumente „[e]uch, die ihr deutsche Biedermänner und nicht lateinische Bösewichter seyd, zu Gefallen [...] deutsch vor[ge]lesen“ ${ }^{81}$ Besonders interessant ist die im Todes-Tempel immer lauter zu Wort kommende Kritik an der Gelehrtenrepublik, die statt an Wissen heranzuführen, dieses eher verdunkele und vertusche, wie dies bereits Ulrich Schmid in Bezug auf David Fassmanns Urteile über seine gelehrten Widersacher konstatiert hat. ${ }^{82}$ Vielleicht hat Schultz Fassmanns Aktivitäten verfolgt, was nicht erstaunlich wäre, wenn man bedenkt, dass er sich im $\mathrm{Ge}$ lahrten Preussen u.a. auch auf Leipziger Zeitschriften bezog.

77 Vgl. PTT. Vierzehnte Unterredung (1730), S. 964.

78 Vgl. Ulrich Schmid: Gespräche aus dem Reiche derer Todten (1718 - 1739). In: Heinz-Dietrich Fischer (Hg.): Deutsche Zeitschriften des 17. bis 20. Jahrhunderts. München 1973, S. 49-59; zur Geschichte des Genres vgl. Nicola Grapp: Fénelon: Dialogues des morts composés pour l'éducationn d'un prince. Studien zu Fénelons Totengesprächen im Traditionszusammenhang. Münster-Hamburg 2001.

79 Vgl. Danuta Hombek: Dzieje Prasy Polskiej. Wiek XVIII (do 1795 r.) [Geschichte der polnischen Presse. Das 18. Jh. (bis 1795)]. Kielce 2016, S. 67, 89.

80 GP. Teil III (Dezember 1723), S. 165.

81 PTT. Erste Unterredung (1728), S. 46.

82 Vgl. Schmid, Gespräche (wie Anm. 78), S. 53 f. 


\section{Neues der Welt (1733-1734)}

Der politischen Berichterstattung mit nur geringem Übergewicht von gelehrten Inhalten verschrieb sich Schultz in seinem letzten Periodikum Neues der Welt, einer Zeitschrift im Quartformat, die zwischen April 1733 und Juli 1734 zweimal in der Woche im Umfang von acht Seiten in Thorn herauskam. ${ }^{83}$

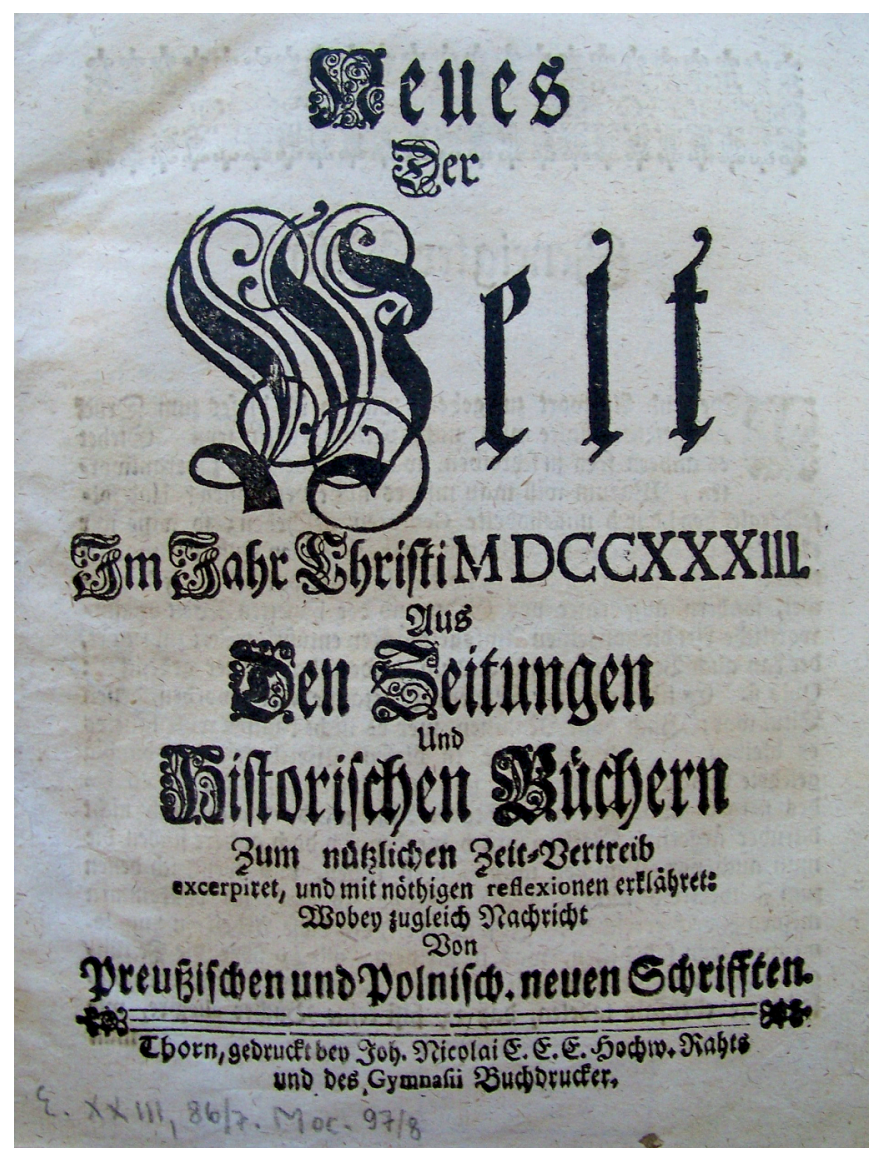

Abb. 5: Titelblatt der ersten Ausgabe von Neues der Welt aus dem Jahr 1733.

83 Die Zeitschrift Neues der Welt [im Folgenden: NDW] ist in der Stadtbibliothek Toruń komplett zu finden (Wojewódzka Biblioteka Publiczna Książnica Kopernikańska. Sign. MAG 101036). Der vollständige Titel lautete: Neues/ Der/ Welt/ Im Jahr Christi MDCCXXXIII./ Aus/ Den Zeitungen/ Und/ Historischen Buechern/ Zum nuetzlichen Zeit-Vertreib/ excerpiret, und mit noethigen reflexionen erklaehret:/ Wobey zugleich Nachricht/Von/ Preussischen und Polnisch. neuen Schrifften. 
Den nur halbgelehrten Charakter sicherte der Redakteur gleich in der Vorrede zur ersten Nummer zu:

Ich verspreche in diesem Wercke keine ausbündig gelehrte Sachen zu tractiren [...]. Insonderheit, da diese Arbeit ein Supplementum seyn soll dessen, was in meinem Collegio über die Zeitungen anzuführen die Zeit nicht zulässet. Vielleicht aber werden diese letztere [geheime Staats Räthe des Apollinis, also Schultz' Widersacher in der Gelehrtenrepublik, Anm. der Vf.] ebenfalls tadelen, daß ich fast keine Bücher allegire, wie man sonst von mir gewohnt ist, und es geschiehet; aber ich habe darzu meine besondere Ursachen, und hoffe, daß sie selbige zu offenbaren nicht verlangen, [...]. Man glaube nur unterdessen, daß ich Bücher habe und selbige so gut, wie andere zugebrauchen gelernet [...]. ${ }^{84}$

Mit journalistischen Arbeitsmethoden beschäftigte sich Schultz in Neues der Welt mehrmals. Informationen bezog er meistens aus den Königsberger Historisch-geographisch und genealogischen Anmerckungen, dem Holländischen Europäischen Mercurius und den Thorner Meletemata Thorunensia.$^{85}$ Er setzte sich aber auch mit dem Wahrheitsgehalt und der Vorgehensweise von Redaktionen anderer zeitgenössischer Periodika auseinander. In einer Kritik an der Gazette de Leyde sagte er sich von Mutmaßungen und Halbwahrheiten los:

Als ich in Holland lebte Studierens halber habe ich oft gehöret, daß der Leydensche ZeitungsSchreiber [...] der Lügner von Leyden genennet worden, und auch auff den Treck-Schuyten mit diesen Charakter öffentlich und gegenwärtig beehrtet worden, worauff er aber nur Antwort gegeben: Die Lügen haben mir mehr eingebracht, als die Wahrheit! Denn der Bogen muß voll seyn, und davor bekomt er Geld: und wenn man einen Bogen durchgelesen, und auff die folgende Zeiten und Advisen achtung giebet, so ist sehr wenig wahr, und denkwürdig; das übrige ist falsch, verdächtig, und bestehet in den Worten: Man sagt; es soll; man muthmaßet; man vermeint; man schreibet; etc. ${ }^{86}$

Ein breites Spektrum an Themen wies bereits das erste Quartal auf - das Blatt füllten Nachrichten aus Polen und Preußen, ${ }^{87}$ dem Reich, ${ }^{88}$ Spanien (der Erbfolgekrieg), ${ }^{89}$ den Niederlanden, ${ }^{90}$ Italien ${ }^{91}$ und Frankreich. ${ }^{92}$ Man berichtete von der Belagerung Orans und widmete der Stadt eine längere Beschreibung, ${ }^{93}$ erklärte den Verlauf der polnischen Königswahl (nach dem Tod Augusts II.) und gängige Prophezeiungen zur polnischen Sukzession, ${ }^{94}$ befasste sich eingehend mit der Cochenille und Johann Philipp Breyns

84 NDW 1 (1733), S. 2f.

85 Vgl. NDW 1 (1733), S. 7; NDW 6 (1733), S. 41-48; NDW 8 (1733), S. 57-64.

86 NDW 9 (1733), S. 67.

87 Vgl. NDW 1 (1733), S. 4f.; NDW 7 (1733), S. 51-56.

88 Vgl. NDW 2 (1733), S. 9-16; NDW 3 (1733), S. $17 \mathrm{f}$.

89 Vgl. NDW 4 (1733), S. 25-32; NDW 5 (1733), S. 33 f.

90 Vgl. NDW 5 (1733), S. 35-39; NDW 7 (1733), S. 49 f.

91 Vgl. NDW 12 (1733), S. 90-96.

92 Vgl. NDW 20 (1733), S. 160; NDW 21 (1733), S. 161-168.

93 Vgl. NDW 5 (1733), S. 40.

94 Vgl. NDW 8 (1733), S. 57-64; NDW, 12 (1733), S. 96. 
Untersuchungen ihrer Entwicklungsstufen, ${ }^{95}$ besonders zerstörerischen Witterungserscheinungen (und klärte dabei seine Leser darüber auf, dass „Einbildung [...] nicht nur ärger als die Pest, sondern auch gefährlicher als der Blitz [ist]“"), ${ }^{96}$ widmete sich dem Liebesleben des sächsischen Kurfürsten, ${ }^{97}$ verfolgte mit ethnographischem Interesse die geheimnisvollen Gepflogenheiten der Thorner Katholiken (in einem Beitrag zur Hl. Barbara-Wallfahrt) ${ }^{98}$ und folgte den besonderen Interessen des Redakteurs, indem man auf „Curirung der Krankheiten durch blosses Anrühren“ aufmerksam machte. ${ }^{99}$ Neues der Welt war somit einerseits ein Nachrichtenblatt, in dem das politische Geschehen in Europa mit Anspruch auf Aktualität dargeboten wurde, andererseits handelte es sich um eine gelehrte Schrift, die vor allem die Errungenschaften der preußischen Wissenschaft in den Blick nahm.

\section{Ausblick und Resümee}

All die von Schultz herausgegebenen Zeitschriften erschienen in Thorn in der Ratsund Gymnasialdruckerei Johann Nicolais. ${ }^{100}$ Gleiches gilt für die sehr unregelmäßig veröffentlichten Meletemata Thorunensia des Thorner Rektors Peter Jaenichen, die den ersten Bögen des Gelahrten Preussen insofern ähnelten, als sie ebenfalls vor allem dem gelehrten Gedankenaustausch dienten. ${ }^{101}$

Während jedoch an den Meletemata kein Anstoß genommen wurde, fand die Publikationstätigkeit des Konrektors des Thorner Gymnasiums zahlreiche Widersacher. Besonders anstößig fand man seine Lebensführung - der zweifache Witwer Schultz lebte mit seiner katholischen Dienstmagd in einer engen Beziehung, war ständig verschuldet und in Erbstreitigkeiten verwickelt. Ferner unterstützte er Pietisten gegen Thorner orthodoxe lutherische Pfarrer, propagierte den Heliozentrismus und gefährdete die Beziehungen zu kronpolnischen Obrigkeiten und Katholiken, indem er die Tabuisierung des Tumults von 1724 missachtete. Dies erklärt auch die allmähliche Abwendung von preußisch-polnischen Angelegenheiten in Schultz Zeitschriften. Weil der Konrektor nie wirklich bereit war, seine wissenschaftlichen und politischen Neigungen zu verbergen, musste er immer wieder Eingriffe der Zensur des

95 Vgl. NDW 13 (1733), S. 99-103; NDW 14 (1733), S. 105-111.

96 NDW 23 (1733), S. 179. Vgl. auch NDW 21 (1733), S. 161; NDW 22 (1733), S. 169-176.

97 Vgl. NDW 25 (1733), S. 193-200; NDW 26 (1733), S. 201-208.

98 Vgl. NDW 14 (1733), S. 111.

99 NDW 21 (1733), S. 168.

100 Vgl. zur Beschreibung der Druckerei: Abriss der thornischen Buchdruckerey oder kurtze Verzeichnüss der darinn sich befindenen Schrifften. Thorn 1717 (Książnica Kopernikańska [Stadtbibliothek Toruń], Sign. KM A. fol. 58 adl. 17) sowie Huppenthal, 400 lat drukarstwa (wie Anm. 11), S. 269-273. 101 Vgl. Meletemata Thorunensia seu Dissertationes varii argumenti ad historiam maxime Polon. et Pussicam, politicam, physicam, rem nummariam, ac literariam spectantes Bd. 1 (1726). Bd. 2 (1727). Bd. 3 (1731). Bd. 4 (1762) [sic!]. 


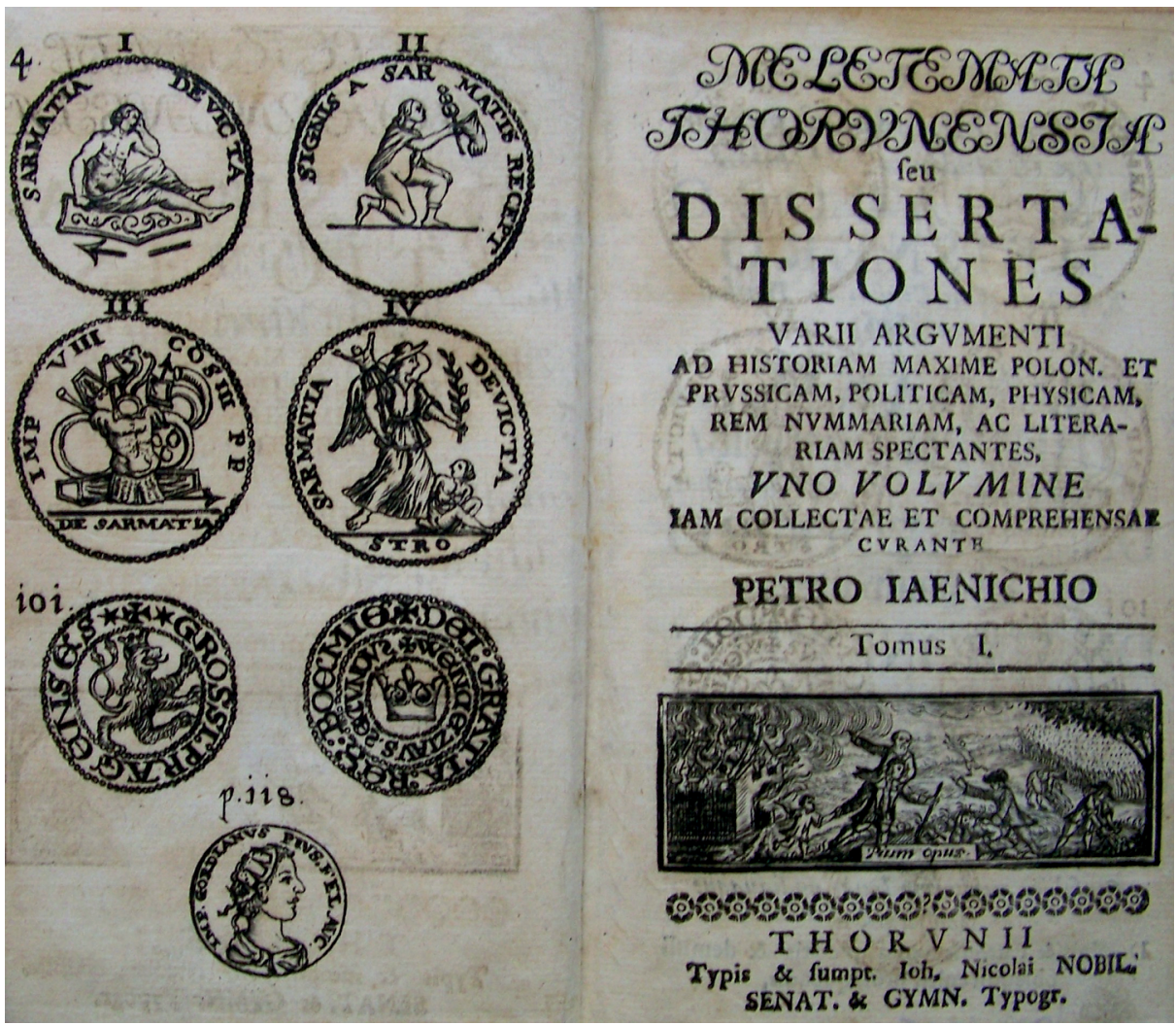

Abb. 6: Titelblatt des ersten Bandes der Meletemata Thorunensia von 1726.

Stadtrates in seine Redaktionsarbeit erleben. ${ }^{102}$ Nach dem Tod Peter Jaenichens wurde er vom Stadtrat nicht (wie erwartet) zum Rektor berufen, sondern zugunsten des weniger anstößigen Peter Zorn übergangen und schließlich 1742 abberufen, woraufhin er Thorn verließ und unter der Schutzherrschaft des Kulmer Bischofs Andrzej Stanisław Załuski zum Katholizismus konvertierte. ${ }^{103}$

Auf dem preußischen Pressemarkt bildeten die Erzeugnisse von Schultz ein besonderes Phänomen insofern, als sie eine Art erste Bestandsaufnahme des Thorner bzw. polnisch-preußischen Pressemarktes darstellten und die Möglichkeiten ausloteten, über welche die Presse als ein Medium des gelehrten Gedankenaustausches verfügte. Der seit 1711 in Thorn tätige Schultz betrachtete seine Zeitschriften, von denen das erste Heft 1722 erschien, zunächst als eine Fortsetzung seines Unterrichts am

102 Vgl. Salmonowicz, Wizerunek żywota Jerzego Piotra Schultza (wie Anm. 38), S. 149-152.

103 Zur Bedeutung Załuskis für das aufklärerische Pressewesen in Polen vgl. auch den Beitrag von Katarzyna Chlewicka in dieser Themenausgabe. 
Gymnasium, wo er vor allem in den Privatstunden ein breites Spektrum neuester Entwicklungen in der Wissenschaft abdeckte. ${ }^{104}$ Sein besonderes Interesse galt der Medizin, ${ }^{105}$ doch er befasste sich auch mit dem Fremdsprachen- und Lateinunterricht sowie mit der Rechtsgeschichte von Polnisch-Preußen. ${ }^{106}$ Mit der Zeit behandelte er in seinen Zeitschriften immer häufiger Themen, mit denen er sich am Thorner Gymnasium nicht durchsetzen konnte, bzw. solche, die er nur im Privatunterricht und mit Schülern, die bei ihm zu Hause untergebracht waren, besprechen konnte. Zeitschriften galten ihm also einerseits als Lehrmaterial, für dessen Einsatz im Unterricht er sich zeitlebens stark machte. Andererseits schien sich Schultz, der über die gelehrten lutherischen Kreise in Preußen zunehmend desillusioniert war, mehr von einer Debatte in der Presse zu versprechen. Seine Herausgebertätigkeit kann also durchaus auch als ein Versuch verstanden werden, die wissenschaftliche Diskussion in die Presse zu verlagern. Von ihr versprach sich der Zeitschriftenmacher mehr Freiheit, sowohl im Hinblick auf die Ausgestaltung und Darbietungsform der gelehrten Inhalte, als auch auf die Reichweite, die im Falle der Zeitschriften immer größer wurde.

Die Abwendung von der Kritik an der Person des Autors und die Bevorzugung einer konstruktiven Kritik an dessen Quellenarbeit sowie von Sachfehlern in dessen Gedankenführung sollten die Zeitschriften aus den Banden der personenbezogenen, politisch und konfessionell gefärbten Streitigkeiten der reichsdeutschen und lokalpreußischen Gelehrtenrepublik lösen. Die unterschiedlichen Formate seiner Periodika, die immer neuen Themenfelder und Genres, die hier zur Geltung kamen, sollten es ermöglichen, eine möglichst diverse Leserschaft in beiden Teilen Preußens zu erreichen und zugleich der städtischen (an der kronpolnischen Erwartungshaltung orientierten) Zensur zu entgehen. Das Scheitern in dieser Hinsicht bezeugt der Ausgang von Schultz' Tätigkeit in Thorn.

Aus einem wenn nicht obrigkeitskonformen, so doch allgemein dem königlichpreußischen Unabhängigkeitsdenken folgenden Zeitschriftenmacher und gefeierten Gelehrten wurde ein Friedensstörer, der als gefährlicher Schulreformer relegiert wurde. Nachfolger auf dem Thorner Zeitschriftenmarkt meldeten sich erst in den 1760er Jahren. Ihre Periodika hatten aber als Rezensionszeitschriften und Intelligenzblätter ein ganz anderes Profil als die hier untersuchten Blätter der Thorner Frühaufklärung.

104 Zum breiten Angebot der Thorner Schule vgl. Schultz' gedrucktes Schreiben in Form eines Briefes an einen Oberst Borck: Hochgebohrner Herr Obrister, Gnädiger Herr [...]. Thorn: Joh. Nicolai 1718 (Wojewódzka Biblioteka Publiczna Książnica Kopernikańska [Stadtbibliothek zu Toruń]. Sign. MAG 115253). Zu Schultz' anonymem Einsatz für den Heliozentrismus vgl. seine Freymüthigen Gespräche über einige neue Sachen aus der Gelahrten Welt [...]. Wittenberg: s. n. 1724 (Wojewódzka Biblioteka Publiczna Książnica Kopernikańska [Stadtbibliothek zu Toruń]. Sign. MAG TN M 149).

105 Vgl. Dissertatio I. De Philosophia Medici [...]. Thorn: Joh. Nicolai 1719 (Wojewódzka Biblioteka Publiczna Książnica Kopernikańska [Stadtbibliothek zu Toruń]. Sign. MAG 2434).

106 Vgl. die Notizen des Gymnasialschülers Ruttig aus dem Jahr 1732 im Staatsarchiv zu Toruń (Archiwum Państwowe w Toruniu). II. VIII. 46: Verschiedene in den polnischen-preussischen Länder zur Anwendung gelangene Rechtsgebräuche. 
